\title{
ĐẶC ĐIỂM LÂM SÀNG, CẬN LÂM SÀNG CỦA NHIỄM CYTOMEGALOVIRUS BẨM SINH TẠI TRUNG TÂM SO SINH BỆNH VIỆN NHI TRUNG ƯƠNG
}

\author{
Nguyễn Thị Quỳnh Nga, Cao Thị Mai Lê \\ Đại học Y Hà Nội
}

\begin{abstract}
TÓM TẮT
Mục tiêu: Mô tả đặc điểm lâm sàng, cận lâm sàng của trẻ sơ sinh mắc CMV bẩm sinh tại Bệnh viện Nhi Trung ương. Phương pháp: Nghiên cứu trên 30 trẻ sơ sinh được chẩn đoán nhiễm CMV bẩm sinh nhập viện tại Trung tâm Sơ sinh, Bệnh viện Nhi Trung ương từ 1/2018 đến 4/2021. Trẻ được đánh giá lâm sàng, cận lâm sàng về bệnh trong thời kỳ sơ sinh. Kết quả: Trẻ nhiễm CMV bẩm

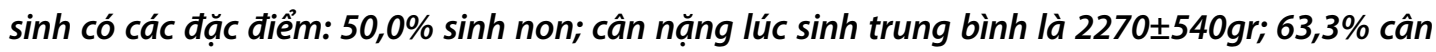
nặng nhỏ hơn so với tuổi thai. Triệu chứng lâm sàng phổ biến của CMV bẩm sinh là vàng da, gan to, lách to gặp ở $43,3 \%$ số trẻ. Giảm tiểu cầu, tăng bilirubin trực tiếp và tăng transaminase có tỷ lệ tương ứng là 63,3\%; 56,7\%; 52,4\%.18/28 (64,3\%) trẻ CMV bẩm sinh có ít nhất một bất thường về hình ảnh thân kinh. 8/15 (53,3\%) trẻ có mất hoạc giảm thính lực trong lần kiểm tra AABR đầu tiên và 14,3\% trẻ có bất thường về mắt. Tỷ lệ CMV-IgM dương tính là 88,5\%. Kết luận: CMV bẩm sinh vẫn là một căn bệnh có tác động gây sinh non, nhẹ cân và các di chứng nặng nề khác trên trẻ sơ sinh. Biểu hiện lâm sàng đa dạng và thường ảnh hưởng lên nhiều cơ quan hệ thống.
\end{abstract}

Từ khóa: Nhiễm trùng bẩm sinh, cytomegalovirus, sơ sinh.

\section{ABSTRACT \\ CLINICAL MANIFESTATIONS AND LABORATORY FINDINGS OF CONGENITAL CYTOMEGALOVIRUS INFECTION IN NEONATOLOGY CENTER OF VIETNAM NATIONAL CHILDREN'S HOSPITAL}

Objectives: To document the clinical manifestations and laboratory findingsof congenital cytomegalovirus infection in the Neonatology Center of National Children's Hospital. Method: Research on 30 newborns were diagnosed with congenital CMV infection admitted to the Neonatal Center, National Children's Hospital from January 2018 to April 2021. Children are evaluated clinically and subclinically for diseases in the neonatal period. Results: Children with congenital CMV infection have the following characteristics: $50.0 \%$ of premature; average birth weight was $2270 \pm 540 \mathrm{gr} ; 63.3 \%$ SGA. Common clinical symptoms at presentation were jaundice, hepatomegaly, and splenomegaly seen in $43.3 \%$ of children. Thrombocytopenia, increased direct bilirubin and increased transaminases were present in $63.3 \% ; 56.7 \% ; 52.4 \%$ respectively. $18 / 28$ (64.3\%) children with congenital CMV infection had at least one neuroimaging abnormality. $8 / 15$ (53.3\%) children had hearing loss or impairment at the first AABR screening and $14.3 \%$ had eye abnormalities. The rate of positive CMV-IgM

Nhận bài: 20-3-2021; Chấp nhận: 15-4-2021

Người chịu trách nhiệm chính: Nguyễn Thị Quỳnh Nga

Địa chỉ: Email: ngaquynh2006@gmail.com 
was $88.5 \%$. Conclusions: Congenital CMV infection remains a disease that impactspreterm birth, low birth weight and other severe sequelae. Clinical manifestations are diverse and often involve systemic effects on multiple organs.

Keywords: Congenital infection, cytomegalovirus, newborn.

\section{1. ĐẠT VẤN ĐỀ}

Nhiễm trùng bẩm sinh vẫn là một vấn đề sức khỏe cộng đồng lớn trên toàn cầu, đặc biệt là ở các nước đang phát triển. Cytomegalovirus (CMV) là nguyên nhân hàng đầu gây nhiễm trùng bẩm sinh trên toàn thế giới, xảy ra ở $0,2 \%-2,2 \%$ trẻ sinh ra sống và được xem là nguyên nhân chính gây ra mất thính lực, khuyết tật thần kinh vĩnh viễn và chậm phát triển ở trẻ em [1], [2], [3]. Cytomegalovirus thường gây nhiễm trùng không triệu chứng mẹ nhưng có thể lây truyền qua nhau thai và tổn thương thai nhi nghiêm trọng, dẫn đến sẩy thai, thai chết lưu và ở những trẻ sinh ra với $C M V$ bẩm sinh, 10 đến $15 \%$ có các triệu chứng sau khi sinh và số còn lại là $\mathrm{CMV}$ bẩm sinh không triệu chứng [4]. Tuy nhiên, gần đây, rất ít báo cáo được công bố tập trung vào các khía cạnh lâm sàng của nhiễm CMV bẩm sinh. Mặc dù nhiễm $\mathrm{CMV}$ bẩm sinh đã được biết đến trong nhiều thập kỷ và các mô tả về các đặc điểm lâm sàng của nó được phổ biến rộng rãi, nhưng điều quan trọng là phải đánh giá gánh nặng của bệnh ở các khu vực khác nhau trên thế giới. Xác định bệnh ở trẻ sơ sinh có ý nghĩa tiên lượng rất lớn, đặc biệt đối với việc đánh giá trẻ sơ sinh có nguy cơ cao về vấn đề phát triển thần kinh. Nghiên cứu các biểu hiện của bệnh giúp định hướng và tập trung quản lý phòng ngừa trong quá trình chăm sóc trẻ, góp phần làm giảm tỷ lệ tử vong và hạn chế di chứng lâu dài ở trẻ em. Do đó, chúng tôi tiến hành nghiên cứu này nhằm mục tiêu: Mô tả đặc điểm lâm sàng, cận lâm sàng của trẻ sơ sinh mắc CMV bẩm sinh tại Bệnh viện Nhi Trung ương từ 1/2018 đến 4/2021.

\section{2. ĐỐITƯợNG VÀ PHƯƠNG PHÁP NGHIÊN CỨU}

\section{1. Đối tượng nghiên cứu}

Trẻ sơ sinh được chẩn đoán nhiễm CMV bẩm sinh nhập viện tại Trung tâm sơ sinh, Bệnh viện Nhi Trung ương từ $1 / 2018$ đến 4/2021 được đưa vào nghiên cứu.

CMV bẩm sinh được xác nhận ở những trẻ sơ sinh được chẩn đoán nhiễm $\mathrm{CMV}$ trong vòng 3 tuần tuổi đầu tiên, chưa được truyền máu nhiều lần trước đó và có ít nhất một tiêu chuẩn xét nghiệm là kháng thể lgM đặc hiệu với $C M V$ dương tính hoặc định lượng DNA-CMV trong máu bằng kỹ thuật Realtime PCR CMV.

\subsection{Phương pháp nghiên cứu: Mô tả cắt ngang.}

Dữ liệu cơ bản được thu thập bao gồm nhân khẩu học, tiền sử bà mẹ, chu sinh và sơ sinh, triệu chứng lâm sàng, các xét nghiệm cận lâm sàng, hình ảnh thần kinh và các thăm khám về mắt và thính lực. Các dấu hiệu và triệu chứng được phân loại bao gồm đẻ non (dưới 37 tuần thai), nhỏ hơn tuổi thai ([SGA] cân nặng lúc sinh nhỏ hơn 10 bách phân vị so với tuổi thai), gan to ( $\geq 3 \mathrm{~cm}$ dưới bờ sườn), lách to (sờ thấy lách trên lâm sàng), chấm xuất huyết/ban xuất huyết trên da, suy hô hấp, nhiễm trùng, giảm tiểu cầu $\left(<100000 / \mathrm{mm}^{3}\right)$, vàng $\mathrm{da}$, tăng bilirubin trực tiếp ( $>3 \mathrm{mg} / \mathrm{dL})$, tăng AST (> $80 \mathrm{U} / \mathrm{L}$ ), tăng ALT (> $80 \mathrm{U} / \mathrm{L}$ ) và hình ảnh thần kinh (vôi hóa quanh não thất, vôi hóa nội sọ, giãn não thất, tăng âm hoặc giả nang quanh não thất, bất thường di trú thần kinh, dị dạng hồi não, teo não v.v.). Các khiếm khuyết giác quan (mất/giảm thính lực, đục thủy tinh thể, viêm màng mạch võng mạc...) được phát hiện bằng ghi điện kích thích thính giác thân não tự động (AABR) và khám chuyên khoa mắt soi đáy mắt bằng Schepens được thực hiện bởi bác sĩ nhãn khoa nhi. 


\subsection{Phân tích số liệu}

Các số liệu được xử lý và phân tích bằng phần mềm SPSS 20.0.

\section{KẾT QUẢ NGHIÊN CỨU}

Trong thời gian từ 01/2018 đến 04/2021 có 30 trẻ sơ sinh đủ tiêu chuẩn chẩn đoán CMV bẩm sinh được đưa vào nghiên cứu.

\section{1. Đặc điểm chung}

Bảng 1. Một số đặc điểm dịch tễ học và nhân trắc của trẻ nhiễm CMV bẩm sinh

\begin{tabular}{|l|c|}
\multicolumn{1}{|c|}{ Đặc điểm } & $\begin{array}{c}\text { Số lượng } \\
\text { (N=30) }\end{array}$ \\
\hline Tuổi mẹ trung bình & $27,0 \pm 6,6$ \\
\hline Con đầu, $n(\%)$ & $16(53,3)$ \\
\hline Đẻ thường, $n(\%)$ & $17(56,7)$ \\
\hline Nam, $n$ (\%) & $16(53,3)$ \\
\hline Tuổi nhập viện trung vị, ngày (IQR)*; (Min-Max) & $2(1-7)^{*} ;(0-21)$ \\
\hline Tuổi thai trung bình, tuần (Min-Max) & $36,8 \pm 2,4(30-41)$ \\
\hline BW trung bình, gr (Min-Max) & $2270 \pm 540(1200-3300)$ \\
\hline
\end{tabular}

*Phân phối của tuổi nhập viện không phải là phân phối chuẩn, IQR: Phần tư dưới, phần tư trên; Min-Max: Giá trị nhỏ nhất-Giá trị lớn nhất.

Nhận xét: Tuổi mẹ trung bình là $27,0 \pm 6,6$ tuổi; $53,3 \%$ trẻ là con đầu và tỷ lệ đẻ thường là $56,7 \%$. Tỷ lệ nam trong nghiên cứu là $53,3 \%$. Giá trị trung vị của tuổi nhập viện của trẻ CMV bẩm sinh là 2 ngày, trong đó có $75 \%$ trẻ nhập viện trong tuần đầu tiên sau sinh. Tuổi thai trung bình là $36,8 \pm 2,4$ tuần. Cân nặng lúc sinh trung bình của trẻ CMV bẩm sinh là $2270 \pm 540 \mathrm{gr}$.

\section{2. Đặc điểm lâm sàng}

Bảng 2. Một số biểu hiện lâm sàng giai đoạn sơ sinh của trẻ nhiễm CMV bẩm sinh

\begin{tabular}{|l|c|}
\hline \multicolumn{1}{|c|}{ Đặc điểm } & $\begin{array}{c}\text { Số lượng (\%) } \\
\mathbf{N = 3 0}\end{array}$ \\
\hline Đẻ non dưới 37 tuần & $15(50)$ \\
\hline SGA & $19(63,3)$ \\
\hline Suy hô hấp & $11(36,7)$ \\
\hline Nhiễm trùng & $13(43,3)$ \\
\hline Vàng da & $13(43,3)$ \\
\hline Ban/chấm xuất huyết & $20(66,7)$ \\
\hline Gan to & $13(43,3)$ \\
\hline Lách to & $13(43,3)$ \\
\hline
\end{tabular}

SGA: Cân nặng lúc sinh dưới bách phân vị thứ 10 so với tuổi thai

Nhận xét: Có 50\% trẻ CMV bẩm sinh đẻ non dưới 37 tuần. Cân nặng lúc sinh của 19 trẻ $(63,3 \%)$ nhỏ hơn 10 bách phân vị so với tuổi thai (SGA). Triệu chứng lâm sàng thường gặp nhất của trẻ $\mathrm{CMV}$ bẩm sinh là ban hoặc chấm xuất huyết dưới da hiện diện ở $66,7 \%$ trẻ. Vàng da và gan lách to xuất hiện ở $43,3 \%$ trẻ. Suy hô hấp và nhiễm trùng cũng là 2 triệu chứng thường gặp khiến trẻ phải nhập viện. 
TẠP CHÍ NHI KHOA 2021, 14, 2

\section{3. Đặc điểm cận lâm sàng}

Bảng 3. Một số xét nghiệm tại thời điểm chẩn đoán của trẻ nhiễm CMV bẩm sinh

\begin{tabular}{|c|c|c|}
\hline Xét nghiệm & Giá trị & Min-Max \\
\hline Bạch cầu (G/L), trung bình & $14,4 \pm 6,7$ & $3,9-31,5$ \\
\hline Hemoglobin (g/L), trung bình & $148 \pm 42$ & $83-237$ \\
\hline Hemotocrit (\%), trung bình & $43,7 \pm 12,3$ & $25,3-69,7$ \\
\hline Tiểu cầu (G/L), trung vị & $63(27-135)$ & $8-681$ \\
\hline $\mathrm{TC}<100 \mathrm{G} / \mathrm{L}, \mathrm{n}(\%)$ & $19 / 30(63,3 \%)$ & \\
\hline $\mathrm{TC}<50 \mathrm{G} / \mathrm{L}, \mathrm{n}(\%)$ & $12 / 30(40,0 \%)$ & \\
\hline AST (U/L), trung vị & $115,1(56,3-212,4)$ & $19,0-493,7$ \\
\hline AST> 80 U/L, n (\%) & $17 / 30(56,7 \%)$ & \\
\hline ALT (U/L), trung vị & $21,0(13,4-73,2)$ & $1,8-557,5$ \\
\hline ALT>80 U/L, n (\%) & $7 / 30(23,3 \%)$ & \\
\hline Bilirubin trực tiếp ${ }^{a}(\mathrm{mg} / \mathrm{dL})$, trung vị & $51,6(24,4-163)$ & $10,2-614,3$ \\
\hline$>3$ mg/dL, n (\%) & $11 / 21(52,4 \%)$ & \\
\hline$>4$ mg/dL, n (\%) & $9 / 21(42,8 \%)$ & \\
\hline Albumin $(g / L)$, trung bình & $33,1 \pm 4,0$ & $22,9-40,3$ \\
\hline CRP định lượng (mg/L), trung bình & $6,0(1,4-18,9)$ & $0,1-124,7$ \\
\hline CMV-IgM dương tính ${ }^{b}, \mathrm{n}(\%)$ & $23 / 26(88,5 \%)$ & \\
\hline CMV-IgG dương tính', n(\%) & $25 / 25(100 \%)$ & \\
\hline PCR CMV máu (cp/ml), trung vị & $7,45 \times 10^{4}\left(2,1 \times 10^{4}-19,6 \times 10^{4}\right)$ & $1860-7,37 \times 10^{3}$ \\
\hline
\end{tabular}

Dữ liệu được trình bày dưới dạng trung bình \pm độ lệch chuẩn với biến có phân phối chuẩn hoặc trung vị (phân tư dưới, phân

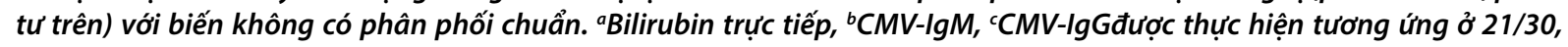
26/30, 25/30 trẻ.

Nhận xét: Giảm tiểu cầu, tăng transaminase và tăng bilirubin liên hợp là những bất thường xét nghiệm thường gặp ở trẻ $\mathrm{CMV}$ bẩm sinh. Tỷ lệ dương tính của xét nghiệm $\mathrm{CMV}$-lgM và $\mathrm{CMV}$-IgG tương ứng là $88,5 \%$ và $100 \%$. Tất cả 30 trẻ đều được làm PCR CMV trong máu, giá trị trung vị tại thời điểm

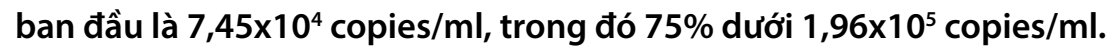

Bảng 4. Một số bất thường về hình ảnh thần kinh và giác quan của trẻ nhiễm CMV bẩm sinh

\begin{tabular}{|l|l|}
\hline \multicolumn{1}{|c|}{ Đặc điểm } & \multicolumn{1}{|c|}{ Số lượng/Tổng (\%) } \\
\hline Bất thường hình ảnh thần kinh: & \\
$\geq 1$ dấu hiệu dưới đây: & $18 / 28(64,3)$ \\
Vôi hóa quanh não thất & $4 / 28(14,3)$ \\
Vôi hóa nhu mô não não & $1 / 28(3,6)$ \\
Giãn não thất & $6 / 28(21,4)$ \\
Teo não, não bé & $2 / 28(7,1)$ \\
Nang/Giả nang quanh não thất & $7 / 28(25,0)$ \\
Xuất huyết não độ I ở trẻ đủ tháng & $4 / 28(14,3)$ \\
\hline
\end{tabular}




\begin{tabular}{|l|l|}
\hline Bất thường về mắt: & $4 / 28(14,3)$ \\
Đục thủy tinh thể & $1 / 28(3,6)$ \\
Viêm màng mạch võng mạc/Thoái hóa võng mạc & $3 / 28(10,7)$ \\
\hline Mất/giảm thính lực: & $8 / 15(53,3)$ \\
Một bên & $5 / 15(33,3)$ \\
Hai bên & $3 / 15(20,0)$ \\
\hline
\end{tabular}

Nhận xét: Tỷ lệ bất thường về hình ảnh thần kinh là 64,3\%, trong đó vôi hóa quanh não thất và nhu mô não được tìm thấy ở $5 / 28$ trẻ $(17,9 \%)$, giãn não thất có ở $6 / 28(21,4 \%)$, não bé trên chẩn đoán hình ảnh phát hiện được 2 trường hợp. Trong số 28 trẻ CMV bẩm sinh được khám chuyên khoa mắt phát hiện 1 trường hợp đục thủy tinh thể và 3 trẻ khác có viêm màng mạch võng mạc hoặc thoái hóa võng mạc. Tỷ lệ mất hoặc giảm thính lực trong giai đoạn sơ sinh phát hiện ở 8/15 (53,3\%) trẻ CMV bẩm sinh.

\section{BÀN LUẬN}

Tỷ lệ giới nam của CMV bẩm sinh là 53,3\%, phù hợp với cơ cấu giới tính lúc sinh. Tỷ lệ đẻ thường là $56,7 \%$, thấp hơn so với nghiên cứu Kylat (2006) là $74 \%$ [5]. Đa số là trẻ nhập viện trong tuần tuổi đầu tiên. Do nghiên cứu được thực hiện tại Bệnh viện Nhi Trung ương, nên phần lớn trẻ đã được nằm viện tại tuyến dưới trước khi chuyển tuyến.

\section{1. Đặc điểm lâm sàng}

Nhiễm CMV bẩm sinh là một nguyên nhân có thể dẫn đến sinh non và thai chậm phát triển trong tử cung. Kết quả nghiên cứu của chúng tôi cho thấy ở trẻ nhiễm CMV bẩm sinh, tỷ lệ sinh non là $50,0 \%$ và $63,3 \%$ trẻ có biểu hiện SGA. Nghiên cứu của Kylat (2006) về nhóm CMV bẩm sinh có triệu chứng có $21 \%$ trẻ đẻ non và $43 \% \mathrm{SGA}$ [5]. Trong nghiên cứu của Boppana (2013) có $50 \%$ trẻ $\mathrm{CMV}$ bẩm sinh có triệu chứng chậm tăng trưởng trong tử cung [6].

Những thay đổi sinh lý bệnh chính của nhiễm CMV bẩm sinh bao gồm xơ hóa các cơ quan như gan, lách, nhau thai. Gan và lách to hơn, xuất hiện hiện tượng xơ hóa và xảy ra quá trình tạo máu ngoài tủy, bao gồm ban xuất huyết dạng "blueberry muffin". Kết quả nghiên cứu của chúng tôi cho thấy tỷ lệ ban xuất huyết hoặc chấm xuất huyết dưới da ở CMV bẩm sinh là $66,7 \%$, tương tự với nghiên cứu của Dreher (2014) và Boppana (2013) [6], [7]. Triệu chứng lâm sàng gan to, lách to trong nghiên cứu là $43,3 \%$, tương đồng với nghiên cứu của Kylat (2006) là 45\%, nhưng cao hơn so với nghiên cứu của Ouellette (2020) và Lanari (2006) là 22-24\% [5], [7], [8]. Vàng da cũng là triệu chứng lâm sàng phổ biến ở trẻ sơ sinh nhiễm CMV bẩm sinh với tỷ lệ là 43,3\%. Tỷ lệ vàng da trong nghiên cứu của Dreher là 40-59\% [7], của Boppana là 67\% [6]. Một số kết quả khác biệt so với nghiên cứu khác có thể do sự khác biệt về thời điểm thăm khám lâm sàng.

Triệu chứng suy hô hấp và nhiễm trùng cũng là triệu chứng hay gặp khiến trẻ ở 2 nhóm bệnh phải nhập viện. Ngoài việc có thể phối hợp với các nhiễm khuẩn khác, phần lớn các bệnh nhân đã nằm viện ở các tuyến dưới trước khi chuyển lên Bệnh viện Nhi Trung ương.

\section{2. Đặc điểm cận lâm sàng}

Các thay đổi sinh lý bệnh trong gan lách to và cường lách ở trẻ nhiễm $\mathrm{CMV}$ bẩm sinh làm phá hủy tế bào dẫn đến giảm tiểu cầu, tăng men gan và tăng bilirubin máu. Trong nghiên cứu của chúng tôi, tỷ lệ giảm tiểu cầu (<100 G/L) là $63,3 \%$, tương đồng với nghiên cứu của Dreher, Boppana [6], [7], nhưng cao hơn so với nghiên cứu của Lanari [9]. Tỷ lệ tăng AST trên $80 \mathrm{U} / \mathrm{L}$ là $56,7 \%$, trong khi tỷ lệ tăng bilirubin trực tiếp là $52,4 \%$, kết quả tương đồng với các tác giả Dreher và Kylat [5], [7]. Từ những thực tế này, một số chỉ số như ban xuất huyết, gan lách to, chức năng gan bất thường, giảm tiểu cầu... có thể giúp bác sĩ nhi khoa định hướng chẩn đoán đến nhiễm trùng bẩm sinh CMV. Tuy nhiên, hầu hết các đặc điểm lâm sàng, cận lâm sàng này là không đặc hiệu.

Trẻ sơ sinh nhiễm trùng $\mathrm{CMV}$ có triệu chứng có nguy cơ cao bị di chứng thần kinh. Nhiều nghiên cứu trước đây đã chỉ ra có đến $90 \%$ trẻ có giảm thị lực, giảm hoặc mất thính lực, chậm 
phát triển tâm thần vận động và những tàn tật khác ở mức độ khác nhau và tỷ lệ tử vong có thể từ 2-30\% [3], [4]. Trong nghiên cứu của chúng tôi có đến $18 / 28$ (64,3\%) trẻ CMV bẩm sinh có ít nhất một bất thường về hình ảnh thần kinh. Kết quả nghiên cứu cũng cho thấy $8 / 15$ (53,5\%) trẻ có mất hoặc giảm thính lực trong lần kiểm tra điện thính giác thân não tự động (AABR) đầu tiên trong giai đoạn sơ sinh, và có $14,3 \%$ trẻ bất thường mắt bao gồm đục thủy tinh thể và viêm màng mạch võng mạc hoặc thoái hóa võng mạc. Nghiên cứu của Ouellette (2020) cho thấy trong nhóm CMV bẩm sinh có triệu chứng tỷ lệ bất thường về hình ảnh thần kinh là $58 \%$ với siêu âm thóp và $89 \%$ với $M R I$ sọ não, trong khi về thính lực, bất thường $A B R$ là 32-45\% [8]. Nghiên cứu của Kylat (2006) cho kết quả có $71,4 \%$ trẻ nhiễm CMV bẩm sinh có triệu chứng có bất thường về hình ảnh $\mathrm{CT}$ sọ não, $89 \%$ bất thường về $M R I$ sọ não, $38 \%$ trẻ bất thường đáp ứng thính giác thân não ( $A B R$ ) và khả năng bất thường về thị giác là $43 \%$ [5]. Nhìn chung, suy giảm thính lực vĩnh viễn là di chứng phổ biến ở trẻ nhiễm CMV bẩm sinh. Nếu không được phát hiện sớm và phục hồi chức năng kịp thời, điều này sẽ dẫn đến suy giảm khả năng nói, ngôn ngữ và khả năng xã hội ở một số lượng lớn trẻ em.

Độ nhạy của xét nghiệm kháng thể IgM đặc hiệu CMV trong nghiên cứu của chúng tôi là $88,5 \%$, phù hợp với nghiên cứu của Ohyama (2019) cho thấy rằng, trong số những trẻ được xác nhân nhiễm CMV bẩm sinh có triệu chứng bằng PCR CMV trong nước tiểu, đô nhay của CMV-lgM là $84,4 \%$, độ đặc hiệu là $99,3 \%$ và giá trị dự đoán dương tính là 96,4\% [10].

\section{KẾT LUÂN}

Trẻ nhiễm CMV bẩm sinh có các đặc điểm lâm sàng: sinh non 50,0\%; cân nặng lúc sinh trung bình là $2270 \pm 540$ gr; cân nặng lúc sinh nhỏ hơn so với tuổi thai $63,3 \%$. Triệu chứng phổ biến khác của nhiễm CMV bẩm sinh giai đoạn sơ sinh bao gồm vàng da, gan to, lách to, giảm tiểu cầu, tăng bilirubin trực tiếp và tăng men gan. Bất thường về hình ảnh thần kinh, giảm thính lực và bất thường về thị giác là các khuyết tật bẩm sinh thường gặp ở trẻ sơ sinh nhiễm CMV bẩm sinh và có thể để lại di chứng nặng nề cho trẻ em.

\section{TÀI LIẸU THAM KHẢO}

1. Conboy T.J., Pass R.F., Stagno S., et al. Early clinical manifestations and intellectual outcome in children with symptomatic congenital cytomegalovirus infection. J Pediatr. 1987, $111(3), 343-348$.

2. Manicklal S., Emery V.C., Lazzarotto T., et al. The "Silent" Global Burden of Congenital Cytomegalovirus. Clin Microbiol Rev. 2013, 26(1), 86-102.

3. Dollard S.C., Grosse S.D., and Ross D.S. New estimates of the prevalence of neurological and sensory sequelae and mortality associated with congenital cytomegalovirus infection. Rev Med Virol. 2007,17(5), 355-363.

4. Boppana S.B., Pass R.F., Britt W.J., et al. Symptomatic congenital cytomegalovirus infection: neonatal morbidity and mortality. Pediatr Infect Dis J. 1992, 11(2), 93-99.

5. Kylat R.I., Kelly E.N., and Ford-Jones E.L. Clinical findings and adverse outcome in neonates with symptomatic congenital cytomegalovirus (SCCMV) infection. Eur J Pediatr. 2006, 165(11), 773-778.

6. Boppana S.B., Ross S.A., and Fowler K.B. Congenital Cytomegalovirus Infection: Clinical Outcome. Clin Infect Dis Off Publ Infect Dis Soc Am. 2013, 57(Suppl 4), S178-S181.

7. Dreher A.M., Arora N., Fowler K.B., et al. Spectrum of Disease and Outcome in Children with Symptomatic Congenital Cytomegalovirus Infection. J Pediatr. 2014,164(4), 855-859.

8. Ouellette C.P., Sánchez P.J., Xu Z., et al. Blood genome expression profiles in infants with congenital cytomegalovirus infection. Nat Commun. 2020,11.

9. Lanari M. Neonatal Cytomegalovirus Blood Load and Risk of Sequelae in Symptomatic and Asymptomatic Congenitally Infected Newborns. Pediatrics. 2006,117(1), e76-e83.

10. Ohyama S., Fujioka K., Fukushima S., et al. Diagnostic Value of Cytomegalovirus IgM Antibodies at Birth in PCR-Confirmed Congenital Cytomegalovirus Infection. Int J Mol Sci. 2019,20(13), 3239. 